\title{
Nonlinearity and Scaling Behavior in a Ferroelectric Materials
}

\author{
Abdelowahed Hajjaji ${ }^{1}$, Mohamed Rguiti², Daniel Guyomar ${ }^{3}$, \\ Yahia Boughaleb ${ }^{4}$ and Christan Courtois ${ }^{2}$ \\ ${ }^{1}$ Ecole Nationale des Sciences Appliquees d'El Jadida,Université d'el Jadida, EL Jadida, \\ ${ }^{2}$ Laboratoire des Materiaux et Procedes, Universite de Lille Nord de France, Maubeuge, \\ ${ }^{3}$ Laboratoire de Genie Electrique et Ferroelectricite (LGEF), \\ Villeurbanne Cedex, Université de Lyon, \\ ${ }^{4}$ Departement de Physique, Faculte des Sciences, \\ Laboratoire de Physique de la Matiere Condensee (LPMC), El Jadida \\ ${ }_{1,4}^{4}$ Morocco \\ 2,3France
}

\section{Introduction}

Due to their electromechanical properties, piezoelectric materials are widely used as sensors and actuators [1-3]. Under low driving levels, their behavior remains linear and can be described by means of linear constitutive equations. A majority of the transducers is used on these levels. Increasing the levels of electric field or stress leads to a depoling that results in the degradation of the dielectric and piezoelectric performances. This latter phenomenon is usually considered to be due to the irreversible motion of the domain walls [4-11]. The resulting nonlinear and hysteretic nature of piezoelectric materials induces a power limitation for heavy duty transducers or a lack of controllability for positioners. Consequently, a nonlinear modeling including a hysteresis appears to be a key issue in order to obtain a good understanding of transducer behavior and to determine the boundary conditions of use.

Several models have been proposed in the literature found understanding the hysteretic behavior of various materials.12-14. However, a majority of these phenomenological models is purely eclectic, and it is consequently difficult to interpret the results as a function of other parameters (stress and temperature) in order to obtain a clear physical understanding.

\section{Stress/electrical scaling in ferroelectrics}

\subsection{Presentation of the scaling law}

In order to determine a scaling law between the electric field and the stress, one should start by following piezoelectric constitutive equations restricting them in one dimension.

These equations can be formulated with stress and electric field as independent variables, thus giving

$$
d S=s_{33}^{E}(E, T) d T+d_{33}(E, T) d E
$$


where $\mathrm{E}, \mathrm{T}$, and $\mathrm{S}$ represent the electric field, the mechanical stress, and the strain, respectively. The constants $\varepsilon_{33}^{T}, s_{33}^{E}$, and $d_{33}$ correspond to the dielectric permittivity, the elastic compliance, and the piezoelectric constant, respectively. Here, the superscripts signify the variable that is held constant, and the subscript 3 indicates the poling direction.

The coefficients are defined as

$$
\begin{gathered}
\frac{d S(E, T=0)}{d E}=d_{33} \\
\frac{d D(E=0, T)}{d T}=\frac{d P(E=0, T)}{d T}=d_{33}
\end{gathered}
$$

From a given $\mathrm{P}$ :

$$
\frac{d S(E, T=0)}{d E}=\frac{d P(E=0, T)}{d T}
$$

It can also be descried as following;

$$
\frac{d S(E, T=0)}{d P(E, T=0)} \frac{d P(E, T=0)}{d E}=\frac{d P(E=0, T)}{d T}
$$

The interrelation between the strain $(\mathrm{S})$ and the spontaneous polarization $(\mathrm{P})$ is estimated using a global electrostrictive relationship, i.e., the strain is an even function of the polarization of the polarization,

$$
S=\sum_{i=0}^{i=2 n} \alpha_{i} P^{i}(E, T=0) \text { with } \mathrm{n} \in \mathrm{N}^{+}
$$

Here, $\mathrm{n}$ is the polynomial order and $\mathrm{a}_{\mathrm{x}}$ is the electrostrictive coefficient of order $\mathrm{x}$.

The derivatives of the strain are

$$
\frac{d S}{d P(E, T=0)}=\sum_{i=1}^{i=2 n} i . \alpha_{i} P^{i-1}(E, T=0)=h(P(E, T=0))
$$

Introducing the attest relationship in the previous calculations leads to:

$$
\begin{gathered}
h(P(E, T=0)) \cdot \frac{d P(E, T=0)}{d E}=\frac{d P(E=0, T)}{d T} \\
\frac{d P(E, T=0)}{d E}=\frac{d P(E=0, T)}{h(P(E, T=0)) d T} \\
\frac{d P(E, T=0)}{d E}=\frac{d P(E=0, T)}{d(h(P(E, T=0)) T)}
\end{gathered}
$$

Thus, 


$$
\Delta E \equiv h(P(E, T=0)) \Delta T \text { and } \Delta T \equiv \frac{\Delta E}{h(P(E, T=0))}
$$

Thus, we consider that the term $\mathrm{h}(\mathrm{P}) \mathrm{T}$ plays the same role to the electric field $E$. This statement is fraught with consequence because this equivalence must be preserved for all cycles $(P, S$ or coefficients). According to the equation (7), the function $\mathrm{h}(\mathrm{P})$ must be odd, so that the effect of "electric field" equivalent reversed with the sign of polarization. Moreover, we know experimentally that the polarization tends to zero when the compressive stress tends to infinity. Moreover, $\mathrm{h}(\mathrm{P})$ to zero when the stress tends to infinity for not polarised ceramics in the opposite direction. Precisely, the equivalence implies that the couple $\left(\begin{array}{l}E=E c \\ P=0\end{array}\right)$ is equivalent to the couple $\left(\begin{array}{l}T=\infty \\ P=0\end{array}\right)$. Hence;

$\lim _{T \rightarrow \infty} h(P) T=E c=>\lim _{T \rightarrow \infty} h(P)=\frac{E c}{T}$.

As illustrated in the figure 1, the scaling law (1) can be used to derive the stress polarization P behavior from the $P=f(E)$ cycle or reciprocally to drive the polarization behavior versus the electrical field once the $P=g(T)$ cycle is known. As it can be seen of figure in the $P=g(T)$ can be obtained from the $P=f(E)$ cycle by streching the $\mathrm{x}$ axis.

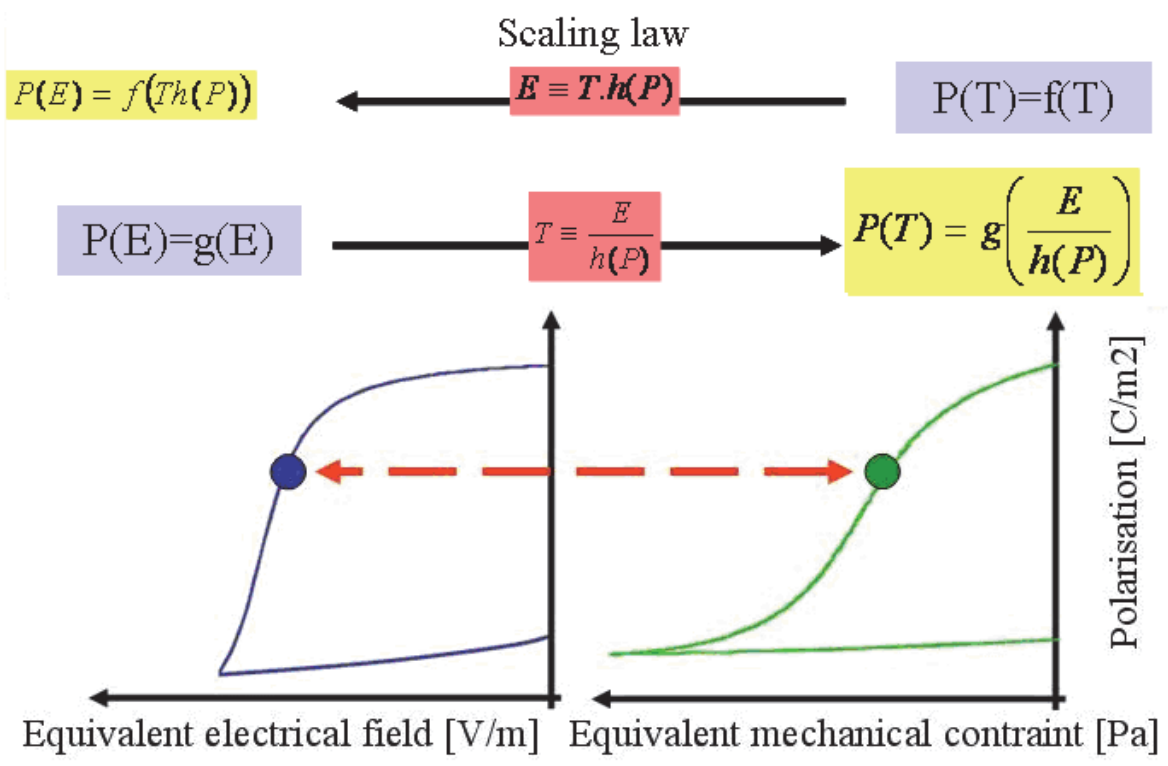

Fig. 1. Schematic illustration of the law scaling (1).

\subsection{Determination of the parameters of the scaling law}

Considering physical symmetries in the materials, a similar polarization behavior $(\mathrm{P})$ can be observed during variation of an electric field (E) or the mechanical stress (T). Both of these external disturbances are caused by the depoling of the sample. An explication concerning how to apply the scaling law is here given based on the equations developed in Sec. II. 
Starting from Eq. (7), the entire derivation of strain by polarization can be calculated based on experimental data, $\frac{d S}{d P(E, T=0)}=h(P(E, T=0))$. In order to determine the right-hand term of Eq. (8) i.e(h(P(E,T=0)), the strain was plotted as a function of the polarization with a variation in electric field. The famous strain-polarization hysteresis loop, shaped as a butterfly - was obtained. It can be approximated by the square of the polarization variation, and neglecting only a small amount of the hysteresis, quadratic electrostriction is obtained, as shown in Fig. 2. A model based on this assumption provides a simplified constitutive law that presents all of the switching behavior in the polarization relation.

Table 1 shows the expression of $\mathrm{h}(\mathrm{P}(\mathrm{E}, \mathrm{T}=0))$ for various structure of ceramics. It is noticeable that the polynomials of $\mathrm{h}(\mathrm{P}(\mathrm{E}, \mathrm{T}=0))$ depend on the structure. The switching of domains and the variation in angles based on the structure (i.e., $90^{\circ}$ and $180^{\circ}$ for a tetragonal material and $71^{\circ}$ and $109^{\circ}$ for a rhombohedral material) were believed to be the cause of the variation in the polynomials. Micromechanics models determine domain switching possibilities with an electromechanical energy criterion with an electrical and a mechanical parameter.12,17 These parameters must be greater than the product of the coercive electric field and the critical value of the spontaneous polarization. The $180^{\circ}, 71^{\circ}$, and $90^{\circ}$ domains play different roles in minimizing the free energy.

\begin{tabular}{ccc}
\hline Material & Structure & Function $\mathrm{h}(\mathrm{P}(\mathrm{E}, \mathrm{T}=0))$ \\
\hline PMN-25PT & Rhomohedral (R) & $0.0589 P^{3}-0.0019 P^{2}+0.0017 P+0.0001$ \\
\hline PMN-40PT & Tetragonal (T) & $0.2933 P^{3}-0.0056 P^{2}+0.0392 P+0.0006$ \\
\hline P188 & MPB (R+T) & $0.056 P$ \\
\hline
\end{tabular}

Table 1.

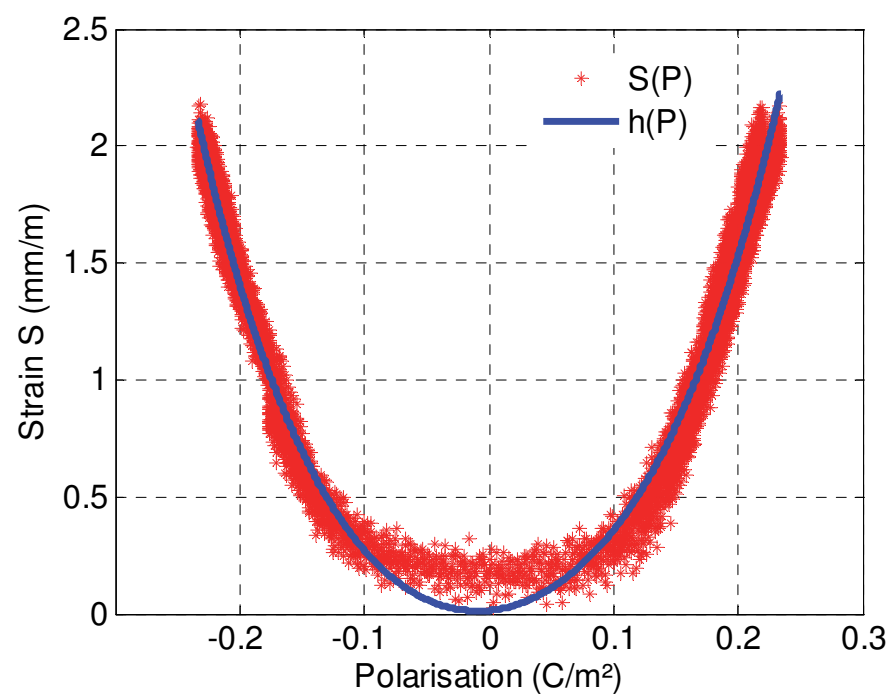

Fig. 2. Strain-electric-displacement hysteresis loops during electric-field loading at zero stress for ferroelectric material. 


\subsection{Verification of the scaling law}

The viability of the proposed scaling law was explored using two distinct experiments on soft PZT. Starting from the experimental depoling under stress $\mathrm{P}=\mathrm{f}(\mathrm{T})$, the depoling was plotted as a function of $h[\mathrm{P}(\mathrm{E}=0, \mathrm{~T})] \mathrm{T}]$ giving $(P=g\{h[P(E=0, T) T]\})$ and was compared to the direct measurement of $\mathrm{P}=\mathrm{g}(\mathrm{E})$. The electric field dependence of polarizations $\mathrm{P}=\mathrm{g}(\mathrm{E})$, was plotted as a function of $E /\{h[P(E, T=0)]\}$ (giving $P=g(E /\{h[P(E, T=0)]\}$ and compared to the direct measurement of $P=f(T)$. This is portrayed in Fig. 1. The second comparison was helpful in determining the appropriateness of the scaling law for fields close to the coercive field (Ec). In this area, a small portion of the curve $\mathrm{P}(\mathrm{E})$ produced a wide range of constraints on the line $\mathrm{P}(\mathrm{T})$ due to $\mathrm{T} \rightarrow \infty$ when $\mathrm{E} \rightarrow \mathrm{Ec}$. These results are presented in Fig. 3

In a general manner, the experimental and reconstructed cycles demonstrated reasonable agreements, with regard to both increasing and decreasing paths, for the soft PZT.

This good agreement for both $\mathrm{P}(\mathrm{E})$ and $\mathrm{P}(\mathrm{T})$ cycles thus confirmed the viability of the scaling law for soft PZT. Only one parameter ruled the "scale" of the strain and the scale of the stress effect. This ease of conversion between $\mathrm{P}(\mathrm{E})$ and $\mathrm{P}(\mathrm{T})$ cycles by such a simple law gives numerous opportunities regarding the use of piezoelectric materials. It is possible to predict the depoling behavior over the entire stress cycle (compressive or tensile)/field plane. These results are important to the design and performance of actuators and sonar transducers.

The proposed scaling law can be used for several electrical models in order to understand the hysteretic behaviour of piezoelectric materials [12-14]. This scaling law is interesting in order to introduce the stress as an equivalent electric field; the behavior of ferroelectric materials under a combined electric field (E) and stress (T) can thus be determined. It is also interesting to note that for practical use, the maximum stress can be determined from this scaling law. This result is presented in Fig. 3. The small variations of polarization were observed for applied electric field lower than $\mathrm{E}_{\mathrm{M}}$ (here, $0.7 \mathrm{kV} / \mathrm{mm}$ ). Therefore polarizations undergo a rapid change in polarization. Based on this $E_{M}$ value, the equivalent stress $\left(T_{M}\right)$ can be directly obtained (40 MPa). As a consequence, the maximum stress for application can be obtained without stress experiment.
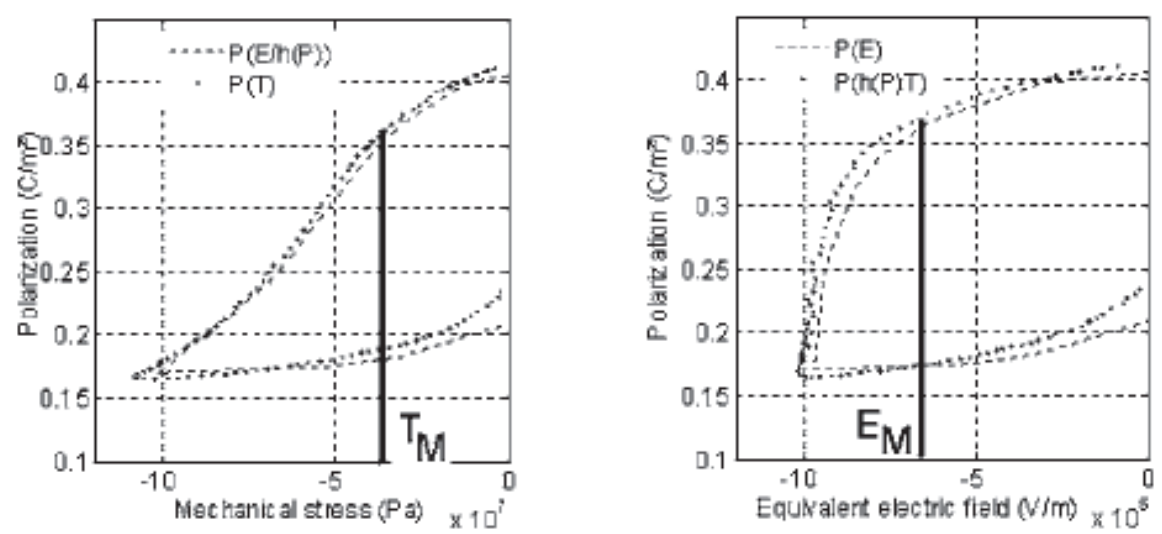

Fig. 3. Experimental validation of the scaling law for soft PZT 


\section{Temperature/electric field scaling in ferroelectrics}

\subsection{Presentation of the scaling law}

In order to determine a scaling law between the electric field and the temperature, one should start by following the piezoelectric constrictive equations, restricting them in one dimension.

These equations can be formulated with the temperature and the electric field as independent variables; thus, giving

$$
\begin{gathered}
d \Gamma=c \cdot \frac{d \theta}{\theta} \cdot d \theta+p \cdot d E \text { and } d D=\varepsilon_{33}^{T} d E+p d \theta \\
D=\varepsilon_{0} E+P
\end{gathered}
$$

$D, P, E, \theta$ and $\Gamma$ and $G$ represent the electric displacement, the polarization, the electric field, the temperature and the entropy, respectively, and where $\mathrm{c}$ and $\mathrm{p}$, respectively, correspond to the heat capacity and the pyroelectric coefficient. Here, the superscripts signify the variable that is held constant, and the subscript 3 indicates the poling direction. Since the polarization is large enough compared to $\varepsilon_{0} E, P \gg \varepsilon_{0} E$, then $D \approx P$.

The coefficients are defined as:

$$
\begin{gathered}
\frac{d \Gamma\left(E, \theta_{0}\right)}{d E}=p \\
\frac{d D\left(E_{0}, \theta\right)}{d \theta}=\frac{d P\left(E_{0}, \theta\right)}{d \theta}=p
\end{gathered}
$$

For a given $\mathrm{P}$ :

$$
\frac{d \Gamma\left(E, \theta_{0}\right)}{d E}=\frac{d P\left(E_{0}, \theta\right)}{d \theta}=p
$$

which can also expressed as:

$$
\frac{d \Gamma\left(E, \theta_{0}\right)}{d P\left(E, \theta_{0}\right)} \frac{d P\left(E, \theta_{0}\right)}{d E}=\frac{d P\left(E_{0}, \theta\right)}{d \theta}=p
$$

Here, $\theta_{0}$ and $E_{0}$ correspond to room temperature $(298 \mathrm{~K})$ and the initial electric field (0 $\mathrm{kV} / \mathrm{mm}$ ), respectively.

From a physical point of view, the entropy cannot depend on the polarization orientation in the ferroelectrics material. It means that the entropy must be an even function of polarization. Limiting the entropy expansion to the second order and ensuring

$$
\Gamma=\alpha P+\beta \cdot P^{2}
$$

Here, $\alpha$ and $\beta$ are a two constant.

The derivatives of the strain can be written as:

$$
\frac{d \Gamma}{d P\left(E, \theta_{0}\right)}=\alpha+2 \beta \cdot P\left(E, \theta_{0}\right)
$$


Introducing Eq. (19) in the previous calculations leads to:

$$
\begin{gathered}
\alpha+2 \cdot \beta \cdot P\left(E, \theta_{0}\right) \cdot \frac{d P\left(E, \theta_{0}\right)}{d E}=\frac{d P\left(E_{0}, \theta\right)}{d \theta}=p \\
\frac{d P\left(E, \theta_{0}\right)}{d E}=\frac{d P\left(E_{0}, \theta\right)}{\left(\alpha+2 \cdot \beta \cdot P\left(E, \theta_{0}\right)\right) d \theta}=p
\end{gathered}
$$

The function $\alpha+2 \cdot \beta \cdot P\left(E, \theta_{0}\right)$ does not depend on temperature.

Thus, Eq. 21 can be written as

$$
\frac{d P\left(E, \theta_{0}\right)}{d E}=\frac{d P\left(E_{0}, \theta\right)}{d\left(\alpha+2 \cdot \beta \cdot P\left(E, \theta_{0}\right) \cdot \theta\right)}=p
$$

According to Fig. 4, for a given value of polarization $(\mathrm{P})$, we can write the following equality $P=d P\left(E, \theta_{0}\right)=d P\left(E_{0}, \theta\right)$

Thus,

$$
\left.\Delta E \equiv \alpha+2 \cdot \beta \cdot P\left(E, \theta_{0}\right)\right) \cdot \Delta \theta \text { and } \Delta \theta \equiv \frac{\Delta E}{\left.\alpha+2 \cdot \beta \cdot P\left(E, \theta_{0}\right)\right)}
$$

With; $\Delta E \equiv E-E_{0}=E$ and $\Delta \theta=\theta-\theta_{0}$

The term $\left.\alpha+2 \cdot \beta \cdot P\left(E, \theta_{0}\right)\right) \cdot \Delta \theta$ can thereby be considered to play an equivalent role as that of the electric field $(\Delta E)$. Such a statement is fraught with a consequence, since this equivalence must be preserved for all cycles $\left(P, \Gamma\right.$ or coefficients). Moreover, $\left(\alpha+2 \cdot \beta \cdot P\left(E, \theta_{0}\right)\right) . \Delta \theta$ is equal to $\alpha . \Delta \theta_{C} \quad\left(\alpha \times \Delta \theta_{C}=E_{C}, P=0\right)$ when the temperature tends to Curie temperature $\left(\theta_{C}\right)$. The equivalence thus precisely implies that the couple $\left(\begin{array}{l}E=E c \\ P=0\end{array}\right)$ is equivalent to the couple $\left(\begin{array}{c}\theta=\theta_{C} \\ P=0\end{array}\right)$. Hence;

$$
\left.\lim _{\theta \rightarrow \theta_{C}}\left(\alpha+2 \cdot \beta \cdot P\left(E, \theta_{0}\right)\right) \cdot \Delta \theta\right)=E_{C}=>\lim _{\theta \rightarrow \theta_{C}}\left(\alpha+2 \cdot \beta \cdot P\left(E, \theta_{0}\right)\right)=\frac{E_{C}}{\Delta \theta_{C}}=\alpha
$$

As illustrated in Fig. 4, the scaling law can be used to derive the behavior of the polarization as a function of the temperature $\mathrm{P}(\theta)$ from $\mathrm{P}(\mathrm{E})$ cycle, or reciprocally to drive the polarization behavior versus the electrical field, once the $\mathrm{P}(\mathrm{E})$ cycle is known.

\subsection{Verification of the scaling law}

The effects of various electric fields and temperatures on the polarization profile are illustrated in Figure 5, where Figure 5(a) represents the polarization variation as a function of the temperature for an electric field $E=0 \mathrm{~V} / \mathrm{mm}$. It was shown by Hajjaji et al [15] that the depolarization as a function of the temperature was mainly due to the decrease in the dipole moment and the fact that the variation in this dipole moment was reversible. In the vicinity of the ferroelectric to paraelectric transition, the temperature depolarization of the ceramics 


$$
\begin{aligned}
& \left.\left.E \equiv \alpha+2 \cdot \beta \cdot P\left(E, \theta_{0}\right)\right) \cdot \Delta \theta \longleftarrow P(E) \equiv \alpha+2 \cdot \beta P\left(E, \theta_{0}\right)\right) \cdot \Delta \theta \\
& \Delta \theta \equiv \frac{}{\left(\alpha+2 \beta \cdot P\left(E, \theta_{0}\right)\right)} \longrightarrow P(\Delta \theta) \equiv \frac{\Delta E}{\left(\alpha+2 \beta \cdot P\left(E, \theta_{0}\right)\right)}
\end{aligned}
$$

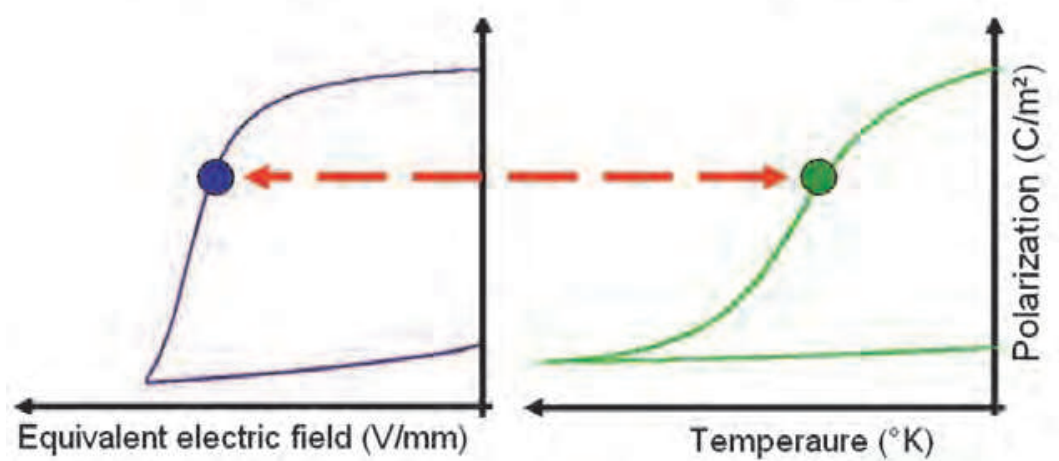

Fig. 4. Schematic illustration of the temperature/electric field scaling law

was the result of a $0-90^{\circ}$ domain switching, whereas a $0-180^{\circ}$ domain switching did not occur with temperature. The effects were thus quite obvious. At a fixed $\theta$ (cf. Fig. 2(b)), the polarization variation was minor for low applied electric fields. It then began to increase as E increased gradually from $350 \mathrm{~V} / \mathrm{mm}$ (a value close to Ec). For the electric field, the depolarization of the ceramic was governed by the domain wall motion. As demonstrated by Pruvost et al.[27], the depolarization process under an electric field was more complicated than its counterpart under a compressed stress or temperature in the sense that the electric field depolarization involved more than one mechanism. For electric tetragonal ceramics; there existed three possibilities for domain switching: $0-90^{\circ}, 90-180^{\circ}$, and $0-180^{\circ}$. It should be pointed out that the focus of the present study was to investigate the characteristics of the polarization variation when the sample was in a stable state. For this, the employed fields $(E)$ were below $450 \mathrm{~V} / \mathrm{mm}(\mathrm{E}<\mathrm{Ec})$ and the temperature dependence took place below $373 \mathrm{~K}$.

Despite the difference between the mechanisms of depolarization as a function of electric field and temperature, we have try determining a law that links the two (electric field $\mathrm{E}$ and temperature $\theta$ ) and to identify one from another.

In order to obtain a suitable scaling relation for the ceramic, one can first follow the suggested scaling law given in Eq. (23). This enables a direct determination of the proportionality coefficients $\alpha$ and $\beta$ from the experimental data. The coefficient $\alpha$ can be determined from the following equation (24) $\left(\frac{E_{C}}{\Delta \theta_{C}}=\alpha=4300\right)$. According to Fig 5(a and b), a plot of the eclectic field $(\Delta E)$ as a function of $\Delta \theta$ renders it possible to obtain the coefficient $\beta(\beta=3000)$. Based on the plot in Figure 3, it was revealed that the experimental data could be fitted (with $\left.R^{2}=0.99\right)$, within the measured uncertainty, by: $\Delta E=\left(\alpha+2 \cdot \beta \cdot P\left(E, \theta_{0}\right)\right) \cdot \Delta \theta$.

In addition, the viability of the proposed scaling law was explored by way of two distinct experiments on soft PZT. Starting from the experimental depoling under temperature $P(\theta)$, 
the depoling was plotted as a function of $\left(\alpha+2 . \beta \cdot P\left(E_{0}, \theta\right) \times \Delta \theta\right)$ (giving $\mathrm{P}\left(\alpha+2 . \beta P\left(E_{0}, \theta\right) \times \Delta \theta\right)$ and was compared to the direct measurement of $P(E)$. The experimental result under an electric field, $P(E)$, was plotted as a function of $\frac{E}{\left(\alpha+2 \cdot \beta \cdot P\left(E, \theta_{0}\right)\right)}$ (giving $P\left(\frac{E}{\alpha+2 \cdot \beta \cdot P\left(E, \theta_{0}\right)}\right)$ ) and was compared to the direct measurement of $\mathrm{P}(\theta)$. This is depicted in Figure4.

The second comparison was helpful in determining the appropriateness of the scaling law for fields close to the coercive field $\left(E_{c}\right)$. In this area, a small portion of the curve $P(E)$ produced a wide range of temperatures on the line $P(\theta)$, due to $\theta \rightarrow \theta_{C}$ when $E \rightarrow E c$ (cf. Figures 6 and 7). In a general manner, the experimental and reconstructed cycles were in reasonably good agreement, with regard to both increasing and decreasing paths. This decent correlation for both the $P(E)$ and $P(\theta)$ cycles thus confirmed the viability of the scaling law.
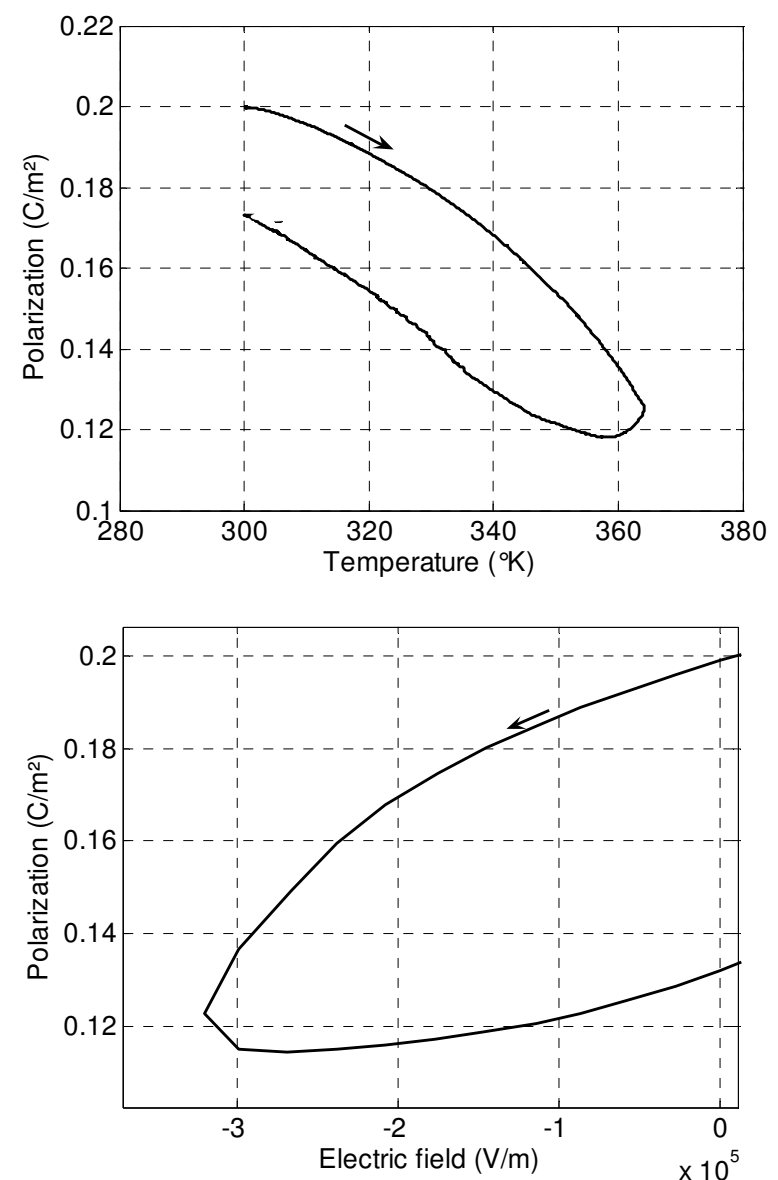

Fig. 5. (a) Polarization versus electric field on $\mathrm{Pb}\left(\mathrm{Mg}_{1 / 3} \mathrm{Nb}_{2 / 3}\right)_{0.75} \mathrm{Ti}_{0.25} \mathrm{O}_{3}$ ceramic. (b) Polarization versus temperature on $\mathrm{Pb}\left(\mathrm{Mg}_{1 / 3} \mathrm{Nb}_{2 / 3}\right)_{0.75} \mathrm{Ti}_{0.25} \mathrm{O}_{3}$ ceramic 


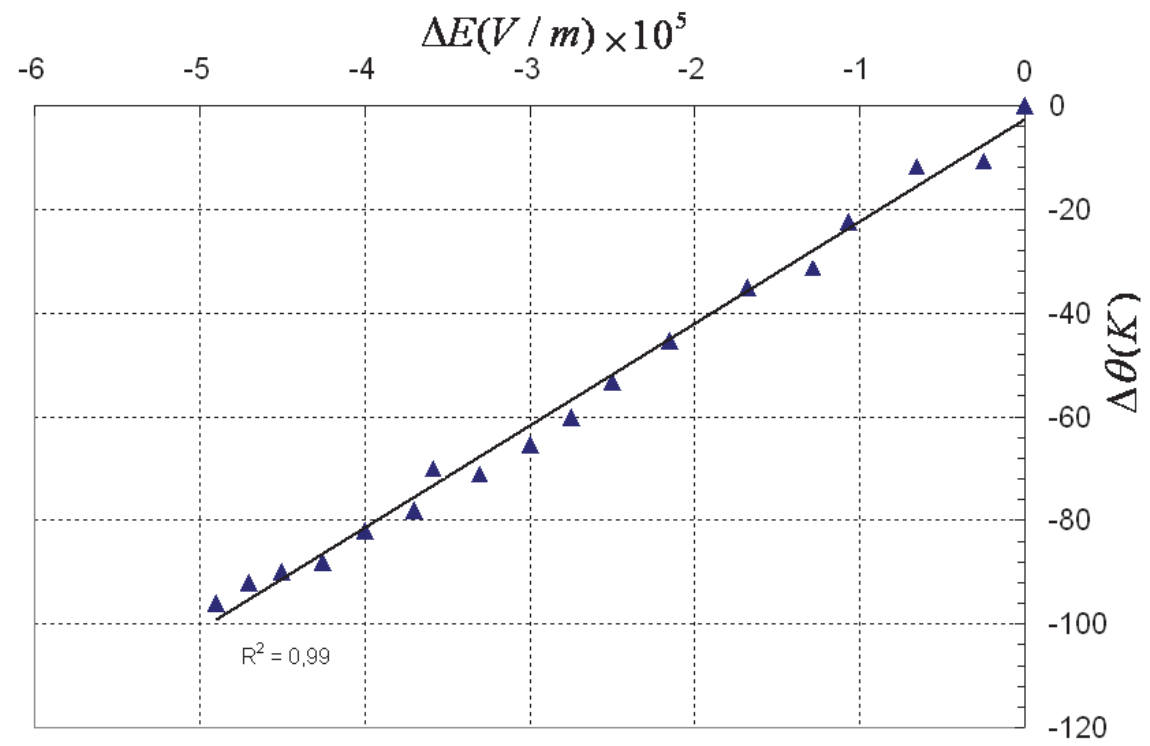

Fig. 6. Scaling of electric field against $(\Delta \theta)$ for $\mathrm{Pb}\left(\mathrm{Mg}_{1 / 3} \mathrm{Nb}_{2 / 3}\right)_{0.75} \mathrm{Ti}_{0.25} \mathrm{O}_{3}$ ceramic

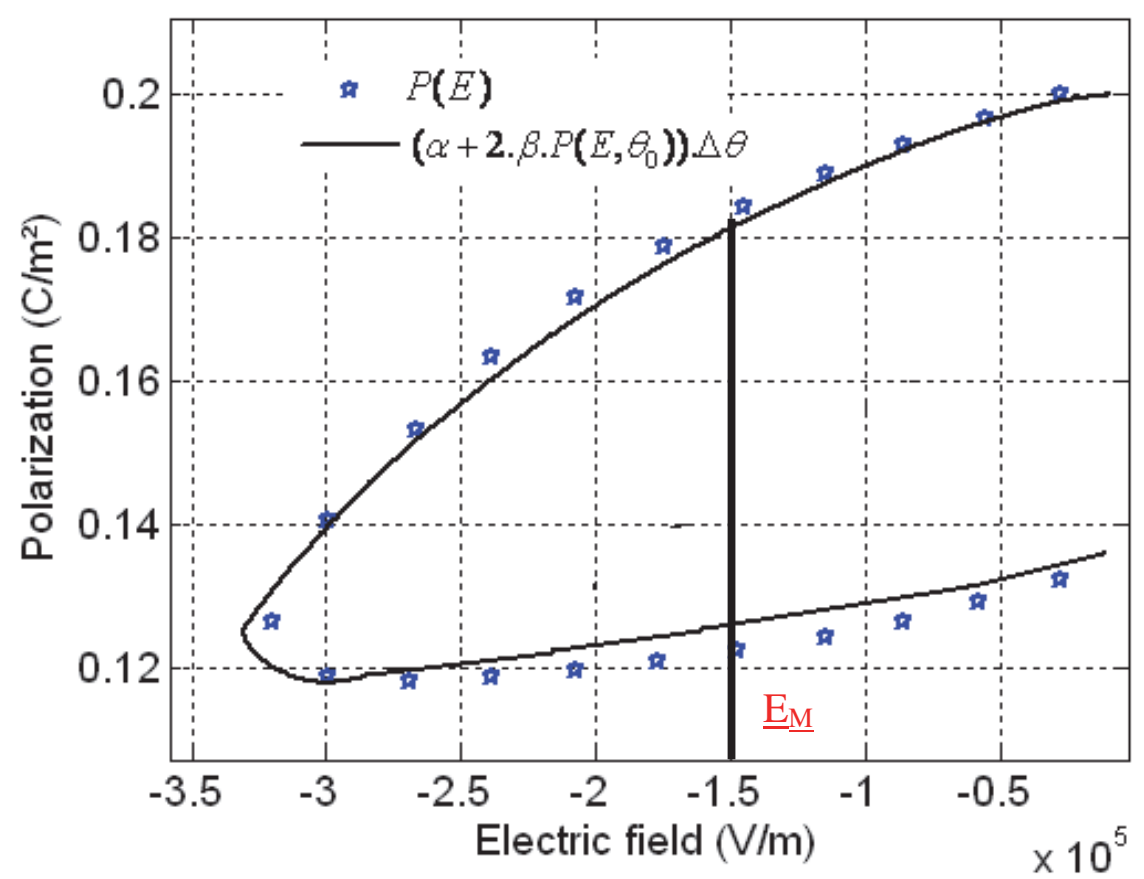

Fig. 7. Experimental validation of the scaling law for PMN-25PT ceramic 
It is interesting to note that for purely electrical measurements, the presented law rendered it possible to determine the maximum temperature for practical use (cf. Figure 7). Small variations in polarization were observed for an applied electric field lower than $E_{M}$ (here, $150 \mathrm{~V} / \mathrm{mm}$ ), leading to the conclusion that the polarizations underwent a rapid change. Based on the obtained $E_{M}$ value, one can determine the equivalent temperature $\left(\theta_{M}\right)$ corresponding to the maximum temperature used.

The relationship $\Delta \theta=\frac{E}{\alpha+2 \cdot \beta \cdot P\left(E, \theta_{0}\right)} \quad$ leads to both a negative, i.e., $\Delta \theta_{\min }=\frac{E_{\min }}{\alpha+2 \cdot \beta \cdot P\left(E_{\min }, \theta_{0}\right)}$, and a positive, i.e., $\Delta \theta_{\max }=\frac{E_{\max }}{\alpha+2 \cdot \beta \cdot P\left(E_{\max }, \theta_{0}\right)}$, bound. The absolute value of $\Delta \theta_{\min }$ can thus be considered to be much larger than $\Delta \theta_{\max }$. Consequently, a symmetric electrical field cycle would give rise to a dissymmetric cycle in terms of temperature. Reciprocally, a symmetric temperature cycle would result in an asymmetric cycle in terms of the electrical field.

\section{Temperature/stress scaling in ferroelectrics}

\subsection{Presentation of the scaling law}

In order to determine the general laws between the mechanical stress, electrical field, and the temperature, we are based on previous studies of Guyomar et al [7]. These studies were proposed a scaling effect between electric field and a term composed by the polarization multiplied by the stress:

$$
\Delta E \equiv \alpha \Delta T \times P\left(E, T_{0}\right)
$$

Where $\alpha$ is the proportionality constant between $\Delta \mathrm{E}$ and $\Delta \mathrm{T}$. Both $\Delta \mathrm{E}$ and $\Delta \mathrm{T}$ represent the electric field and the mechanical stress variation. $\mathrm{P}\left(\mathrm{E}, \mathrm{T}_{0}\right)$ is the polarization at zero stress $\left(\mathrm{T}_{0}=0 \mathrm{MPa}\right)$.

In the other study Hajjaji et al proposed a scaling law between the electrical field and the temperature [16]. This law is expressed by the following expression.

$$
\Delta E \equiv\left(\chi+2 \beta \times P\left(E, \theta_{0}\right)\right) \times \Delta \theta
$$

Here, $\chi$ and $\beta$ are a two constant. $\mathrm{P}\left(\mathrm{E}, \theta_{0}\right)$ is the polarization at room temperature ( $\left.\theta_{0}=298 \mathrm{~K}\right)$ and $\Delta \theta$ is the temperature variation.

In most cases the coefficient $\chi$ is negligible compared to $2 \beta \times P\left(E, \theta_{0}\right)$. Thus, the expression (26) becomes:

$$
\Delta E \equiv\left(2 \beta \times P\left(E, \theta_{0}\right)\right) \times \Delta \theta \text { and } \Delta \theta \equiv \frac{\Delta E}{\left(2 \times \beta . P\left(E, \theta_{0}\right)\right)}
$$

With; $\Delta E \equiv E-E_{0}=E$ and $\Delta \theta=\theta-\theta_{0}$

According to equations (25) and (27) we find the following expression:

$$
\Delta E \equiv \alpha \Delta T \times P\left(E, T_{0}\right) \equiv 2 \beta \times P\left(E, \theta_{0}\right)
$$




$$
\begin{gathered}
P\left(E, T_{0}\right)=P\left(E, \theta_{0}\right) \\
\alpha \Delta T \equiv 2 \beta \Delta \theta
\end{gathered}
$$

With; $\Delta E \equiv T-T_{0}=T$ and $\Delta \theta=\theta-\theta_{0} \quad\left(\theta_{0}=298 K\right)$

Thus

$$
T \equiv \delta \times \Delta \theta
$$

As illustrated in figure 8, we determine $\mathrm{P}(\mathrm{T})$ and $\mathrm{P}(\theta)$ from $\mathrm{P}(\mathrm{E})$ (steps 1 and 3 ), $\mathrm{P}(\mathrm{E})$ and $\mathrm{P}(\theta)$ from $\mathrm{P}(\mathrm{T})$ (steps 1 and 2 ), and at the end we can determine $\mathrm{P}(\mathrm{E})$ and $\mathrm{P}(\mathrm{T})$ from $\mathrm{P}(\theta)$ (steps 2 and 3$)$,.

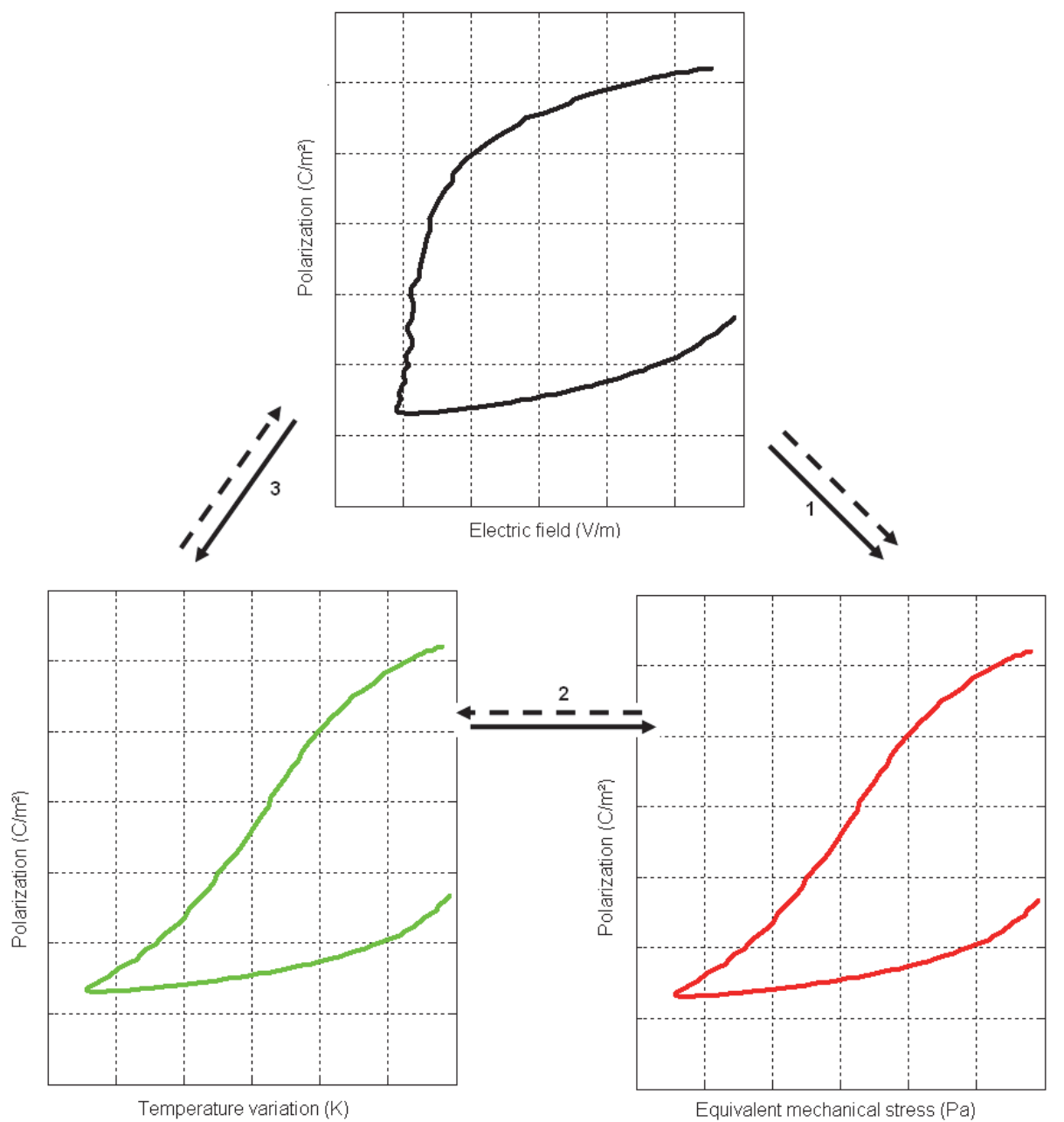

Fig. 8. Schematic illustration of the scaling laws 


\subsection{Verification of the scaling law}

Figure 9 shows the relation between $\Delta \mathrm{T}$ and $\frac{\Delta E}{P\left(E, T_{0}\right)}$ where good linear fits are apparent $(R$ close to 1). This implies a power-law relation between the mechanical stress and electric field, i.e., $\left(\Delta E \equiv \alpha \Delta T \times P\left(E, T_{0}\right)\right.$, the exponent $\alpha$ can be extracted from the slope, i.e. $\alpha=\frac{d\left(\frac{(\Delta E)}{P\left(E, T_{0}\right)}\right)}{d(\Delta T)}$.

The expression (25) allows expressing the mechanical stress as an equivalent electric field and the electric field as an equivalent stress. Thus, a good agreement between electrical field and mechanical stress proved that the proposed scaling law allows predicting the depoling behavior under stress using only purely electrical measurements. Reciprocally, the predictions of the depoling behaviour under an electrical field were permitted using only purely mechanical measurements. It was found that such an approach permitted the prediction of the maximal stress application from purely electrical measurements (i.e., measurements of $\mathrm{S}(\mathrm{E})$ and $\mathrm{P}(\mathrm{E})$ ). The maximal stress for application is the stress that can be applied to materials without they lose their piezoelectric properties.

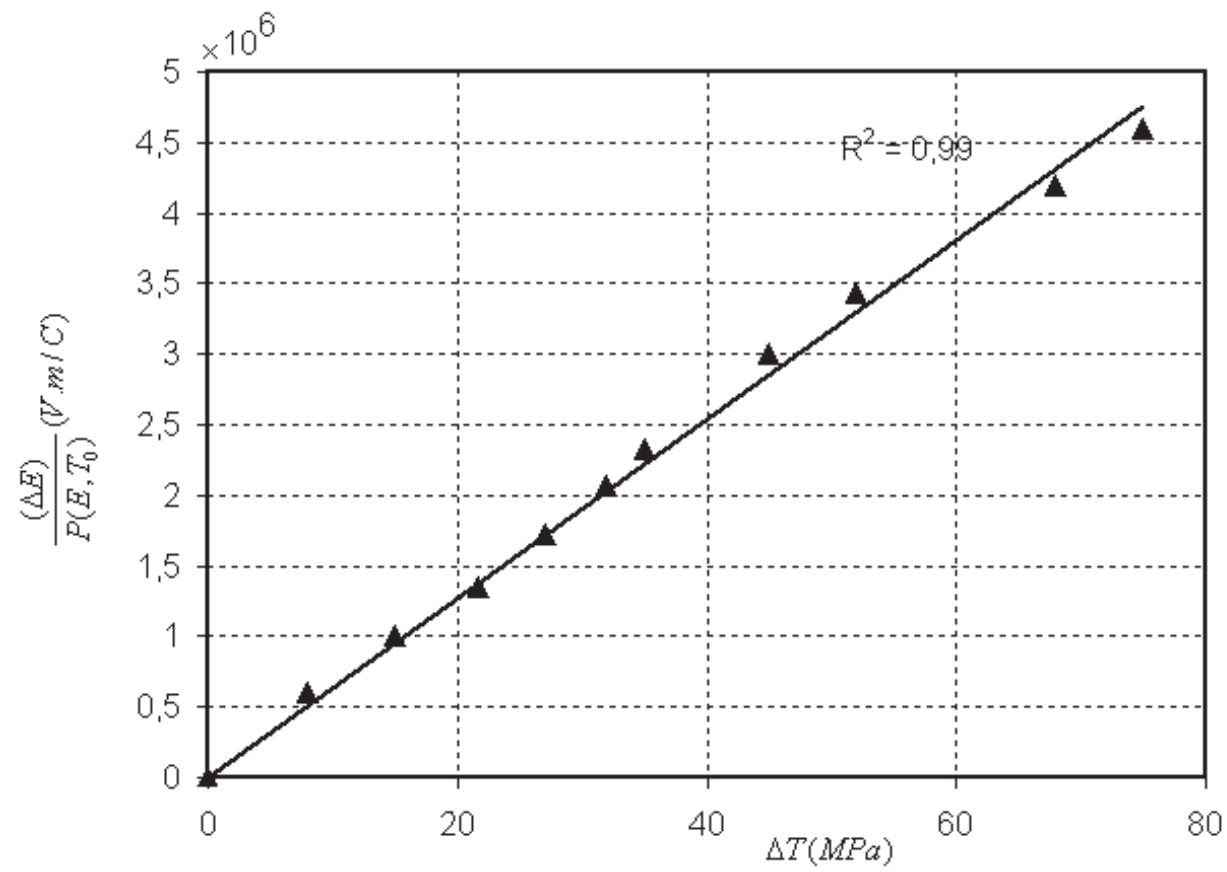

Fig. 9. Experimental validation of the scaling law between electrical field and mechanical stress for PZT ceramic

In the other study we proposed a scaling law between the electrical field and the temperature [16]. This law is expressed by the expression (25) $\left(\Delta E \equiv\left(2 \beta \times P\left(E, \theta_{0}\right)\right) . \Delta \theta\right)$. 
Figure 10 shows the relation between $\frac{\Delta E}{P\left(E, \theta_{0}\right)}$ and $\Delta \theta$ where good linear fits are apparent ( $R$ close to 1$)$. This implies a power-law relation between the temperature and electric field, i.e., $\left(\Delta E \equiv\left(2 \beta \times P\left(E, \theta_{0}\right)\right) . \Delta \theta\right)$, the exponent $\beta$ can be extracted from the slope, i.e. $2 \beta=\frac{d\left(\frac{\Delta E}{P\left(E, \theta_{0}\right)}\right)}{d(\Delta \theta)}$.

According to this law, it is possible to determine the behavior of the polarization in function of temperature from the electrical measurements. Reciprocally, it is possible to determine the behavior of the polarization in function of the electric field from thermal measurements. It is interesting to note that for purely electrical measurements, the presented law rendered it possible to determine the maximum temperature for practical use. Small variations in polarization were observed for an applied electric field lower than $E_{M}$ (here, $150 \mathrm{~V} / \mathrm{mm}$ ), leading to the conclusion that the polarizations underwent a rapid change. Based on the obtained $E_{M}$ value, one can determine the equivalent temperature $\left(\theta_{M}\right)$ corresponding to the maximum temperature used.

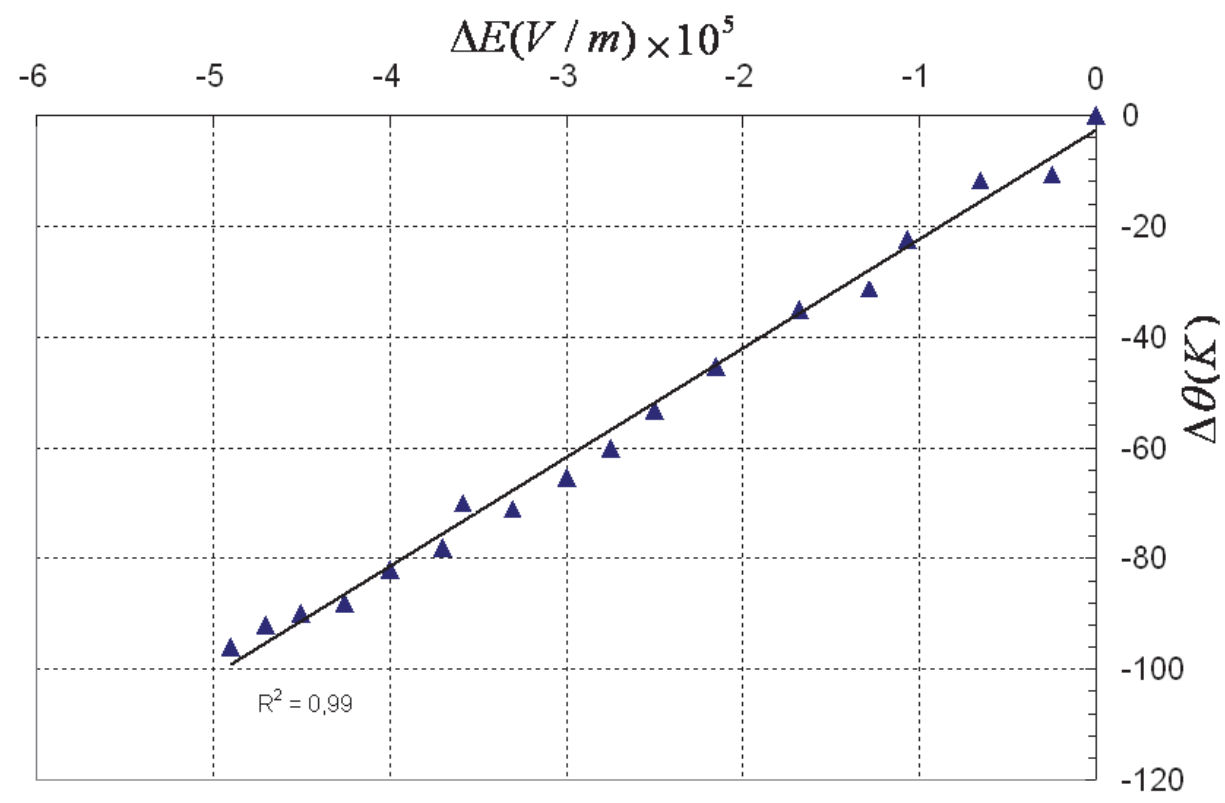

Fig. 10. Experimental validation of the scaling law between electrical temperature variations for PZT ceramic

Considering physical symmetries, similar behaviors can be observed under stress or temperature. Indeed both external disturbances may result in depling of the sample. We consider here a scaling effect that is described with (equation 30): $T \equiv \delta \times \Delta \theta$.

Where $\mathrm{T}$ is the mechanical stress, $\Delta \theta$ the temperature variation, and $\delta$ the scaling parameter. We therefore explore the viability of this assumption using two distinct 
experiments on the same PZT material. We record first the depoling under mechanical stress. In a second time, we record the depoling under temperature. We try to obtain the same depoling values under mechanical stress or temperature in order to compare therefore the scaling effect. Starting from the experimental depoling under mechanical stress $\mathrm{P}(\mathrm{T})$, we plot the depoling as a function of “ $\frac{T}{\delta}$ " $\mathrm{P}\left(\frac{T}{\delta}\right)$ and is compared to direct measurement $P(\Delta \theta)$. In the same manner the the experimental result under stress $\mathrm{P}(\Delta \theta)$ is plotted as a function of $\delta \times \Delta \theta$ (giving $\mathrm{P}(\delta \times \Delta \theta)$ ) and compared to the direct measurement $\mathrm{P}(\mathrm{T})$. In figure 4 are shown these results. The agreement is outstanding considering the different natures of mechanical stress and temperature. The two external disturbances acts very differently on the domain configurations [8-11], but at the macroscopic scale, over an important averaging, it is shown here that a very sharp scaling law can be considered. It is important to note the consequences of such a scaling once it has been demonstrated experimentally. It is possible to predict the poling behavior over the entire stress/temperature plane as shown on figure 11.

In order to confirm these results, we plotted the mechanical stress as a function to the temperature variation. Figure 12 shows the relation between $\Delta \theta$ and $T$, where good linear fits are apparent ( $R 2$ close to 1 ). This implies a power-law relation between the stress and temperature, i.e., $(T \equiv \delta \times \Delta \theta)$, the exponent $\delta$ can be extracted from the slope, i.e. $\delta=\frac{d(T)}{d(\Delta \theta)}$. According to figure 12, the coefficient $\delta$ is equal to $0.35 \times 10^{6}$.
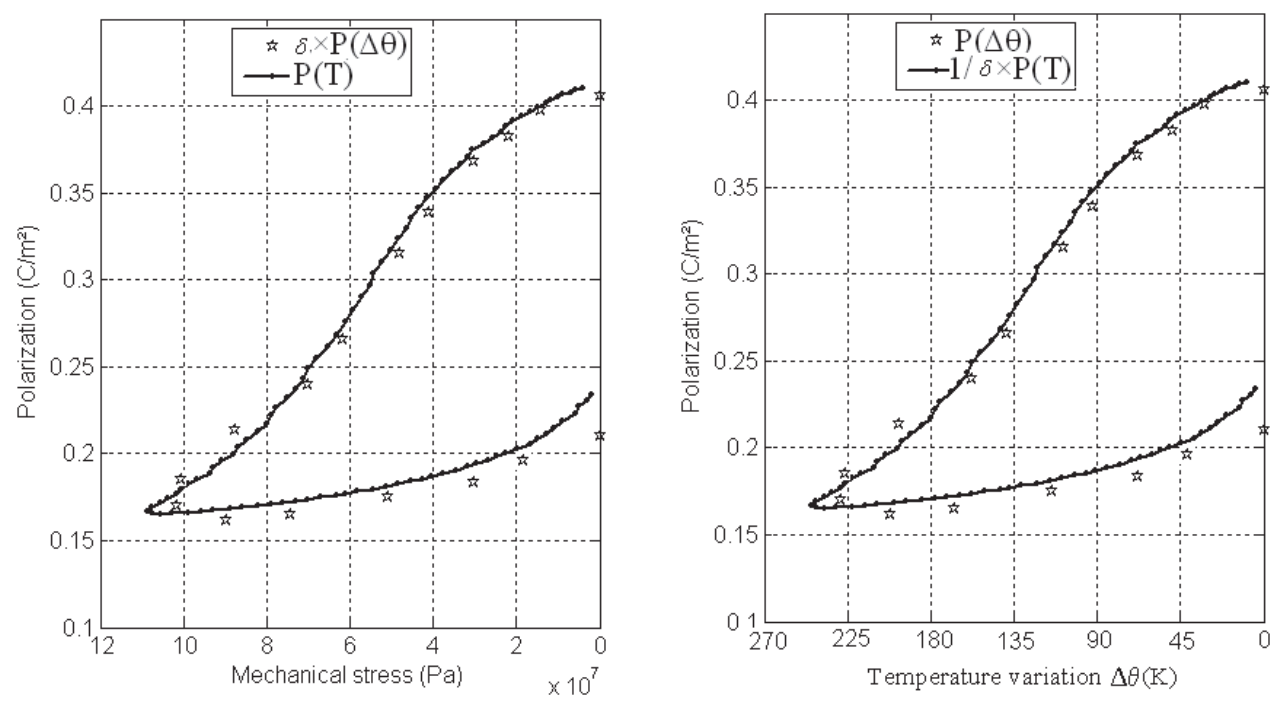

Fig. 11. Experimental validation of the scaling law for soft PZT ceramic.

In the literature, a majority of these phenomenological models are purely electric, mechanic, or thermal [19-22]. Consequently, it is difficult to interpret the results as a function of the combined to two or three excitations (mechanical stress and temperature for example). 
The proposed scaling law can be used for several models have been proposed in the literature for comprehending the hysteretic behavior of various materials, which renders it interesting for introducing the temperature as an equivalent to the mechanical stress, or reciprocally to introducing the mechanical stress as an equivalent to the temperature.

The behavior of ferroelectric materials under a combined mechanical stress $(\mathrm{T})$ and temperature $(\theta)$ can thus be determined, which will help in the identification and understanding of the effect of the simultaneous action of temperature and mechanical stress on ceramics.

According to this law, it is possible to determine the behavior of the polarization in function of temperature from the mechanical measurements. Reciprocally, it is possible to determine the behavior of the polarization in function of the mechanical stress from thermal measurements. It is interesting to note that for purely mechanical measurements, the presented law rendered it possible to determine the maximum temperature for practical use, and reciprocally it is possible to determine the maximum stress for practical use from purely thermal measurements.

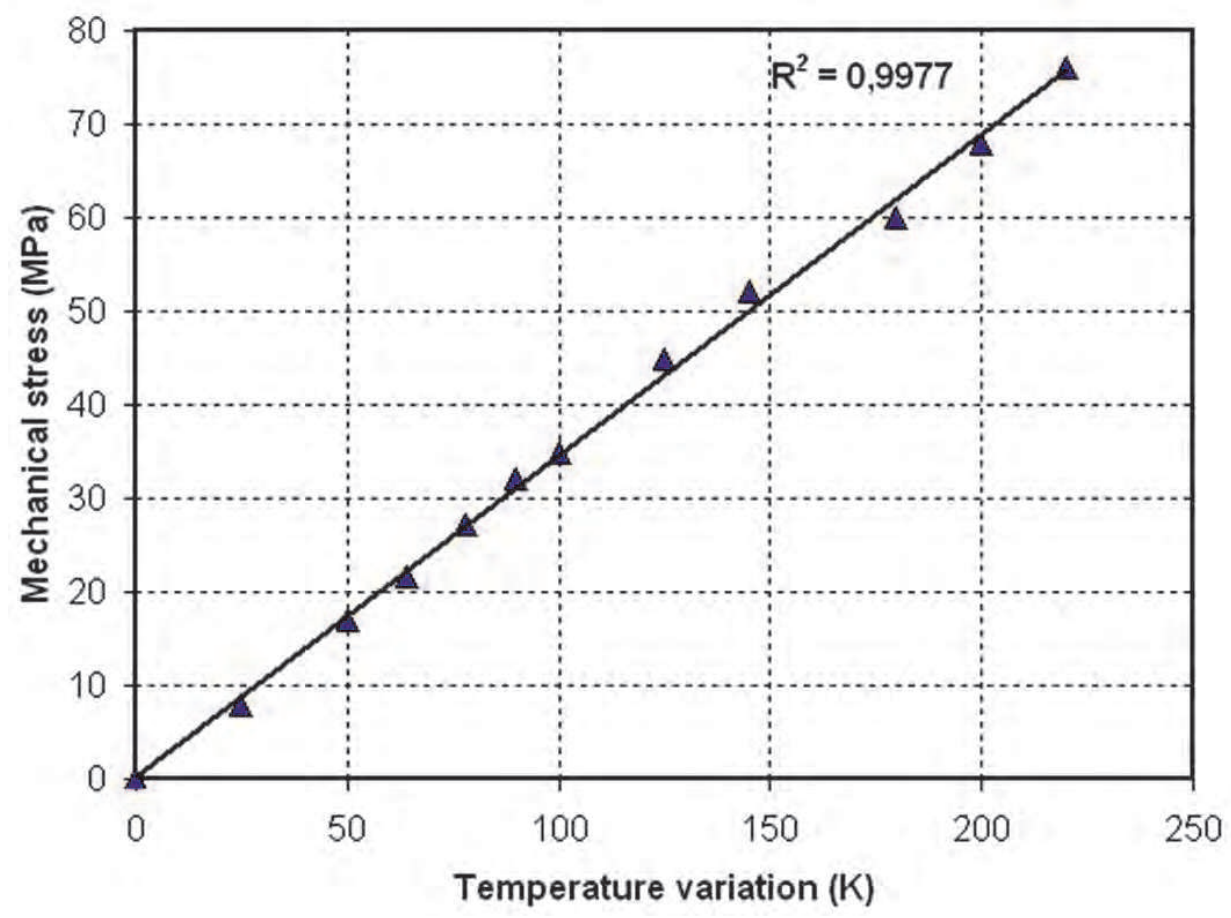

Fig. 12. Experimental validation of the scaling law between mechanical stress and temperature variation for PZT ceramic

\section{Predictions of material behavior}

Due to their electromechanical properties, piezoelectric materials are widely employed as sensors and actuators [16-17]. Most of these piezoelectric materials are utilized under 
different conditions (stress, electrical field, and temperature).It would thus be interesting to predict their behaviors under a variety of excitations without having to perform too much experimental work, i.e., just carrying out a single experiment and providing the other experimental values. For example, from a simple measurement of the polarization as a function of the electric field, one could predict the behavior of the polarization as a function of temperature negative and positive(step 2) and stress (compressive and tensile stress) (step 1). In conclusion, we could determine $P(T)$ and $P(\theta)$ from $P(E)$ (steps 1 and 3), $P(E)$ and $P(\theta)$ from $\mathrm{P}(\mathrm{T})$ (steps 1 and 2 ), and finally $\mathrm{P}(\mathrm{E})$ and $\mathrm{P}(\mathrm{T})$ from $\mathrm{P}(\theta)$ (steps 2 and 3 ),

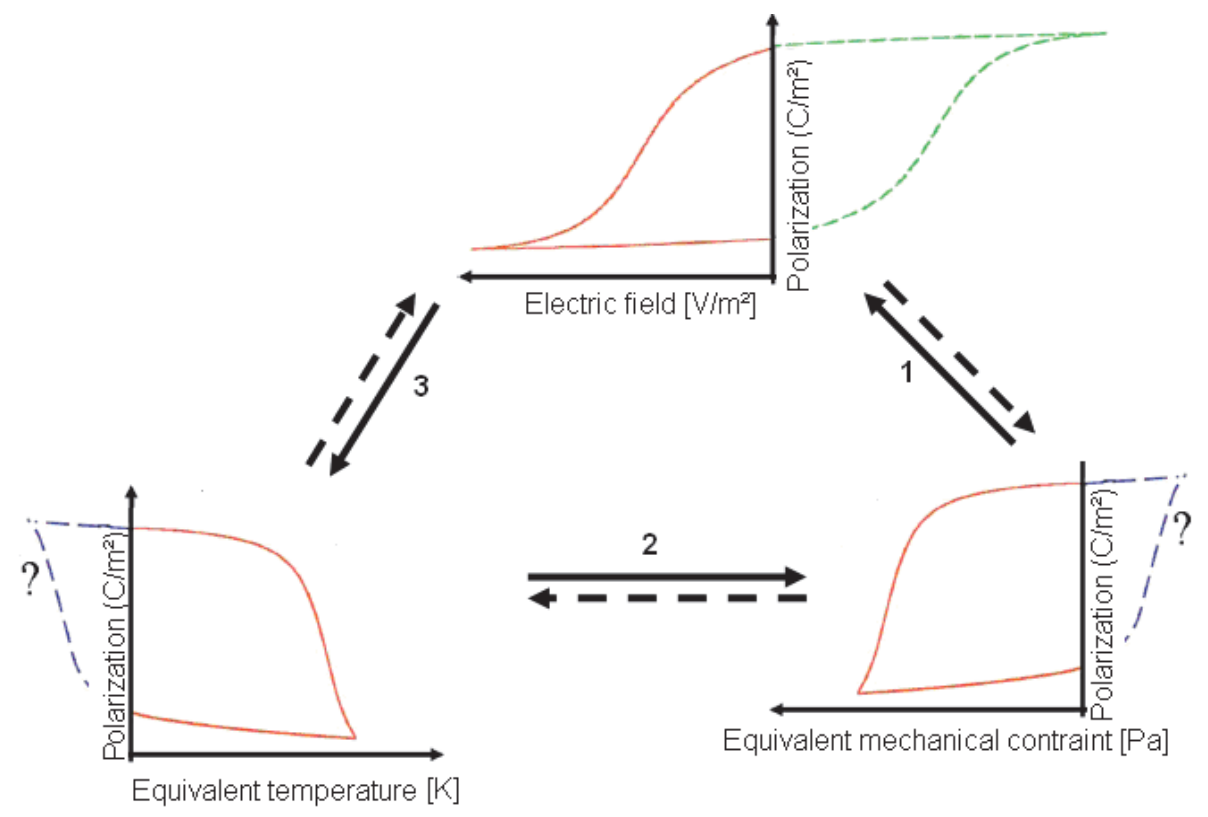

Fig. 13. Schematic illustration of the material behavior under excitations.

\section{Relationship between the coefficients $d_{33}$ and $\varepsilon_{33}$}

The proposed scaling law can also be applied to the minor cycles. This fact provides a great advantage for the problem of the relation between $\varepsilon_{33}$ and $d_{33}$ according to

$$
\begin{gathered}
\varepsilon_{33}=\frac{\partial P}{\partial E} \\
d_{33}=\frac{\partial P}{\partial T}
\end{gathered}
$$

It is quite difficult to experimentally obtain a real $\mathrm{d} 33$ corresponding to an exact $\varepsilon_{33}$. During the experiment, the electrical field (E) was stopped at a certain level to obtain a value of the polarization $(P)$, and the permittivity $\left(\varepsilon_{33}\right)$ could thus be defined. When $E$ was stopped, $d_{33}$ was calculated based on the obtained $\mathrm{d}_{33}$ and did consequently not correspond to thereal $\mathrm{d}_{33}$. 
As illustrated in Fig. 14, the measuring point for $\mathrm{P}$ was not on the main cycle but slightly beside, on the minor cycle. This result was due to the difference of $\mathrm{E}_{0}+\Delta \mathrm{E}$ from $\varepsilon$, not corresponding to that of $T_{0}+\Delta T$ from $d_{33}$. Resultantly, the calculation of $d_{33}$ could not be based on an exact value. By using the proposed simple scaling law, on the other hand, it was possible to obtain an exact value for $\mathrm{d}_{33}$,

$$
\frac{\partial P}{\partial T}=-h(P) \frac{\partial P}{\partial E}
$$

thus,

$$
d_{33}=-h(P) P \varepsilon_{33} .
$$

Figure 15 depicts the prediction of the piezoelectric constant $\left(\mathrm{d}_{33}\right)$ under a compressive stress. In this case, $d_{33}$ was calculated from the function $h[P(E, T=0)]$ and compared with experimental values. It could be observed that the experimental and calculated piezoelectric constants displayed a similar variation with the compressive stress. Such a good agreement between simulation and experiment proved that the proposed law scaling rendered it possible to predict the piezoelectric constant $\left(\mathrm{d}_{33}\right)$ under stress using only purely electrical measurements. Reciprocally, predictions of the dielectric constant $\left(\varepsilon_{33}\right)$ under an electrical field were permitted using only purely mechanical measurements.

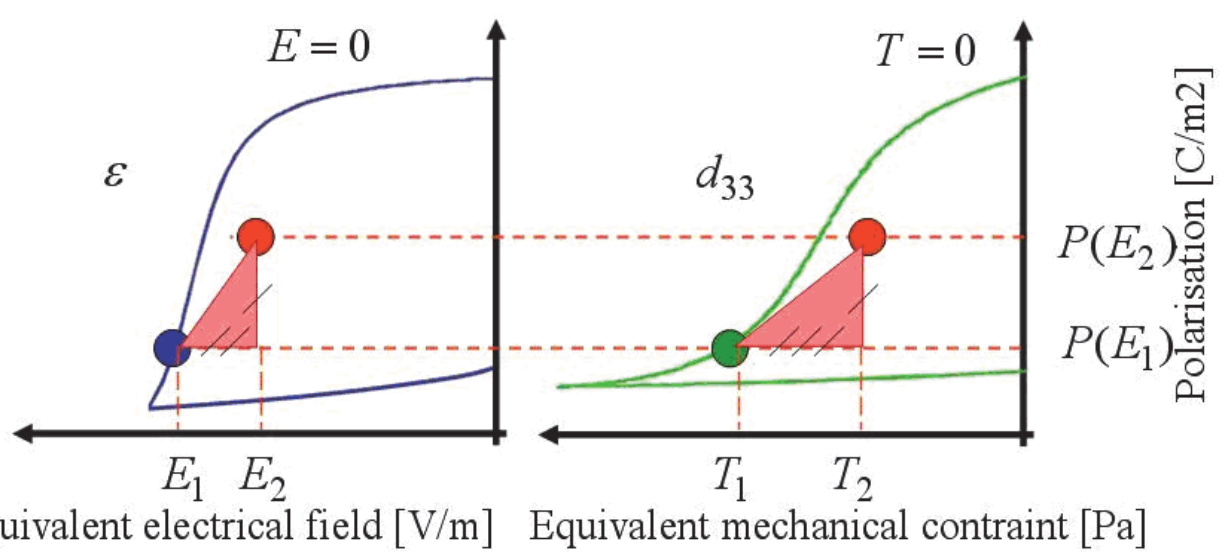

Fig. 14. relation between $\varepsilon_{33}$ et $d_{33}$

\section{Conclusion}

The present chapter proposes a three simple scaling laws taking into account the electrical field, the stress, temperature, and the polarization of ferroelectric materials in the form of $\Delta E \equiv \alpha \Delta T \times P\left(E, T_{0}\right), \Delta E \equiv\left(2 \beta \times P\left(E, \theta_{0}\right)\right) . \Delta \theta$ and $\Delta T \equiv \delta \times \Delta \theta$. The nonlinear behavior was considered and compared to that predicted by a linear reversible constitutive law in order to demonstrate the range of validity of the linear assumptions. 


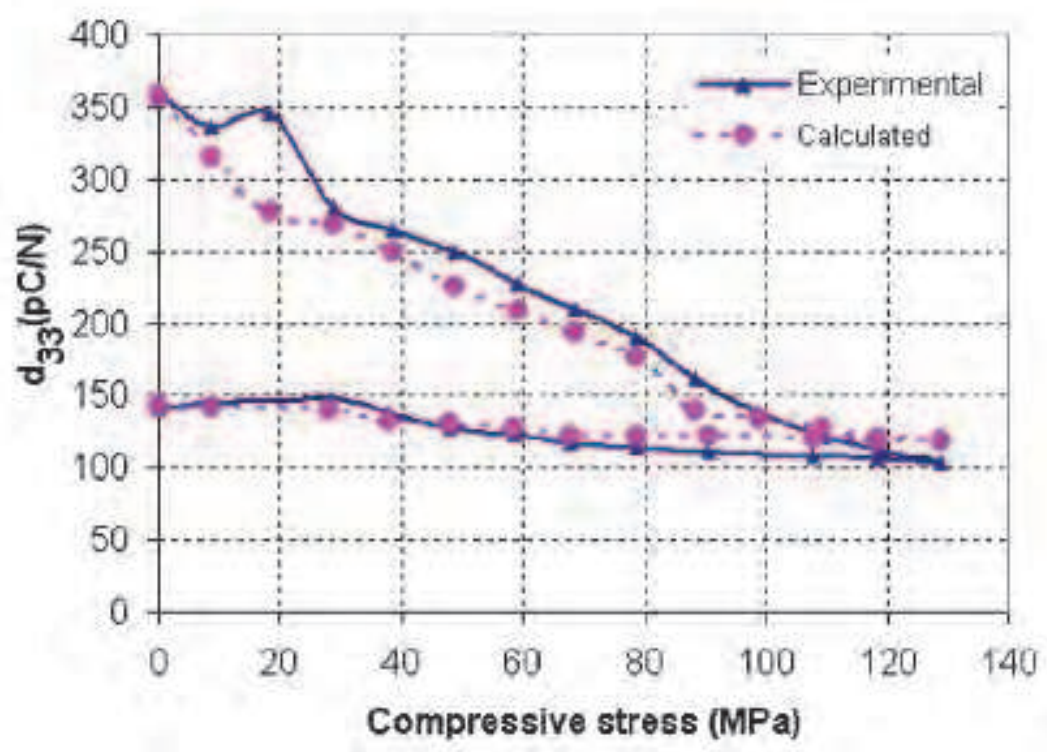

Fig. 15. (Color online) Evolution of the piezoelectric coefficient under compressive stress

The proposed scaling laws can be used for several models have been proposed in the literature for comprehending the hysteretic behavior of various materials, which renders it interesting to interpret the results as a function of the combined to two or three excitations (mechanical stress and temperature for example). The ease of conversion between $\mathrm{P}(\mathrm{E}), \mathrm{P}(\theta)$ and $\mathrm{P}(\mathrm{T})$ cycles by such a simple laws gives numerous opportunities regarding the use of piezoelectric materials. It was possible to predict the depoling behavior over the entire stress cycle (compressive or tensile), or to predict the depoling behavior over the entire temperature cycle (negative or positive) from to the hysteresis cycle. Thus, one should note that applying a symmetric electrical field cycle leads to a dissymmetric cycle under stress and temperature. Consequently, the polarization behaves differently as a function of compressive as opposed to tensile stresses. Moreover, the polarization behaves also differently as a function of positive and negative temperature.

\section{References}

[1] L. E. Cross, Ferroelectrics 76,241 (1987).

[2] G. H. Haertling, J. Am. Ceram. Soc. 82, 797 (1999).

[3] S. E. Park and T. R. Shrout, IEEE Trans. Ultrason. Ferroelectr. Freq.

[4] B. Jaffe, W. R. Cook, and H. Jaffe, Piezoelectric Ceramics Academic, London, (1971)

[5] C. Bedoya, C. H. Muller, J.-L. Baudour, V. Madigou, M. Anne, and M. Roubin, Mater. Sci. Eng., B 75,43 (2000).

[6] E. C. Subbarao, M. C. McQuarrie, and W. R. Buessem, J. Appl. Phys. 28, 1194 (1957).

[7] A. Hajjaji, S. Pruvost, G. Sebald, L. Lebrun, D. Guyomar, and K. Benkhouja, Solid State Sci. 10, 1020 (2008).

[8] S. Pruvost, G. Sebald, L. Lebrun, D. Guyomar, and L. Severat, Acta Mater. 56, 215 (2008). 
[9] vA. E. Glazounov and M. J. Hoffmann, J. Eur. Ceram. Soc. 21, 1417 (2001).

[10] D. Berlincourt, H. Helmut, and H. A. Krueger, J. Appl. Phys. 30, 1804 (1959).

[11] A. Hajjaji, S. Pruvost, G. Sebald, L. Lebrun, D. Guyomar, and K. Benkhouja, Acta Mater. 57, 2243 (2009).

[12] S. C. Hwang, J. E. Huber, R. M. McMeeking, and N. A. Fleck, J. Appl. Phys. 84, 1530 (1998).

[13] T. Steinkopff, J. Eur. Ceram. Soc. 19,1247 (1999).

[14] B. Ducharne, D. Guyomar, and G. Sebald, J. Phys. D 40,551 (2007).

[15] A Hajjaji, S Pruvost, G Sebald, L Lebrun, D Guyomar, K Benkhouja, Acta Mater. 57 (2009) 2243.

[16] A. Hajjaji, D. Guyomar, S. Pruvost, S. Touhtouh, K. Yuse, and Y. Boughaleb, Physica B (2010).

[17] G. H. Haertling, J. Am. Ceram. Soc. 82, 797 (1999).

[18] S.-E. Park and T. R. Shrout, IEEE Trans. Ultrason. Ferroelectr. Freq. Control 44, 1140 (1997).

[19] S. C. Hwang, J. E. Huber, R. M. McMeeking, and N. A. Fleck, J. Appl.Phys. 84, 1530 (1998).

[20] T. Steinkopff, J. Eur. Ceram. Soc. 19,1247 (1999).

[21] B. Ducharne, D. Guyomar, and G. Sebald, J. Phys. D: Appl. Phys. 40,551 (2007).

[22] G. Sebald, S. Pruvost, L. Seveyrat, L. Lebrun, and D. Guyomar, J. Eur. Ceram. Soc. 27, 4021 (2007). 


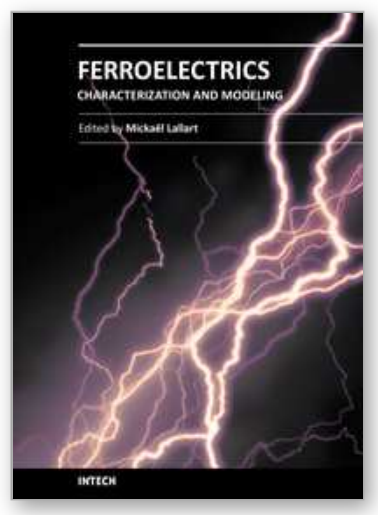

\author{
Ferroelectrics - Characterization and Modeling \\ Edited by Dr. MickaÃ«l Lallart
}

ISBN 978-953-307-455-9

Hard cover, 586 pages

Publisher InTech

Published online 23, August, 2011

Published in print edition August, 2011

Ferroelectric materials have been and still are widely used in many applications, that have moved from sonar towards breakthrough technologies such as memories or optical devices. This book is a part of a four volume collection (covering material aspects, physical effects, characterization and modeling, and applications) and focuses on the characterization of ferroelectric materials, including structural, electrical and multiphysic aspects, as well as innovative techniques for modeling and predicting the performance of these devices using phenomenological approaches and nonlinear methods. Hence, the aim of this book is to provide an up-to-date review of recent scientific findings and recent advances in the field of ferroelectric system characterization and modeling, allowing a deep understanding of ferroelectricity.

\title{
How to reference
}

In order to correctly reference this scholarly work, feel free to copy and paste the following:

Abdelowahed Hajjaji, Mohamed Rguiti, Daniel Guyomar, Yahia Boughaleb and Christan Courtois (2011). Nonlinearity and Scaling Behavior in a Ferroelectric Materials, Ferroelectrics - Characterization and Modeling, Dr. MickaÃ«I Lallart (Ed.), ISBN: 978-953-307-455-9, InTech, Available from:

http://www.intechopen.com/books/ferroelectrics-characterization-and-modeling/nonlinearity-and-scalingbehavior-in-a-ferroelectric-materials

\section{INTECH}

open science | open minds

\author{
InTech Europe \\ University Campus STeP Ri \\ Slavka Krautzeka 83/A \\ 51000 Rijeka, Croatia \\ Phone: +385 (51) 770447 \\ Fax: +385 (51) 686166 \\ www.intechopen.com
}

\author{
InTech China \\ Unit 405, Office Block, Hotel Equatorial Shanghai \\ No.65, Yan An Road (West), Shanghai, 200040, China \\ 中国上海市延安西路65号上海国际贵都大饭店办公楼 405 单元 \\ Phone: +86-21-62489820 \\ Fax: +86-21-62489821
}


(C) 2011 The Author(s). Licensee IntechOpen. This chapter is distributed under the terms of the Creative Commons Attribution-NonCommercialShareAlike-3.0 License, which permits use, distribution and reproduction for non-commercial purposes, provided the original is properly cited and derivative works building on this content are distributed under the same license. 